\title{
O PANHELLENION DE ADRIANO: ESPAÇO, INTEGRAÇÃO E IDENTIDADE NO SÉC. II D.C.
}

\author{
Felipe Perissato ${ }^{1}$
}

Maria Cristina N. Kormikiari Passos ${ }^{2}$

\begin{abstract}
Resumo: A criação do Panhellenion durante o séc. II d.C. foi tanto um projeto de iniciativa imperial quanto das elites provinciais que procuravam integrar a Grécia com o Império Romano. Com função delegada à organização de cultos, de jogos e de festivais pan-helênicos na Grécia, a liga foi um conselho sediado em Atenas que cultivou uma concepção de identidade pan-helênica muito específica. Esse aspecto ficou evidente tanto nas inscriçóes que registram as associações das cidades gregas à liga quanto no programa construtivo empregado em Atenas por Adriano.

Dessa maneira, este artigo tem como objetivo analisar a criação do Panhellenion como um projeto consciente de política identitária, tendo em vista que a liga institucionalizou uma ideia de pan-helenismo decorrente, sobretudo, de uma leitura romana sobre a Grécia. Além disso, a escolha por Atenas como sede do conselho propiciou sua consolidação como ponto convergente da integração das cidades gregas com Roma.

Palavras-chave: Panhellenion, Adriano, Identidade étnica, Grécia romana, Integração mediterrânica, Evergetismo.
\end{abstract}

\section{INTRODUÇÃo}

Há muitas formas de exercer domínio sobre outrem. O Mediterrâneo conquistado por romanos é um exemplo emblemático de como a dominação se manifesta por meio de formas diversificadas e heterogêneas. No séc. II d.C., o imperador Adriano foi responsável por uma série de intervenções políticas nas províncias gregas, o que causou uma grande transformação em seus espaços

1 Mestrando em Arqueologia pelo Museu de Arqueologia e Etnologia da Universidade de São Paulo, membro do Laboratório de Estudos sobre a Cidade Antiga - Labeca - e bolsista FAPESP. Email: felipe.perissato@usp.br

2 Docente em Arqueologia do Mediterrâneo Antigo - Museu de Arqueologia e Etnologia da Universidade de São Paulo. Pesquisadora do Laboratório de Estudos sobre a Cidade Antiga Labeca. https://usp-bracademia.edu/CristinaKormikiari 
urbanos. $\mathrm{O}$ interesse do imperador pela cultura grega é um traço marcante de sua personalidade, sendo até apelidado por alguns contemporâneos como "Graeculus", o pequeno grego (História Augusta, I, 1.5). ${ }^{3} \mathrm{Na}$ historiografia, o imperador ficou ainda conhecido como um dos imperadores "filelênicos" e suas intervenções de grande impacto nas províncias gregas são destaque de seu principado. (BOATWRIGHT, 2000, p. 12-13)

Iniciado nos Mistérios de Elêusis, Adriano visitou a Ática em pelo menos três ocasióes. A primeira viagem ocorreu quando foi nomeado para cargo de arconte em Atenas por volta de 112-113 d.C. (História Augusta, I, 13.1), enquanto que as visitas posteriores ocorreram quando já havia assumido o posto mais alto do Império Romano. Assim, Adriano esteve intimamente ligado às questões políticas da Grécia. Seu olhar atento aos assuntos gregos foi responsável por colocar em prática um amplo programa de construçóes públicas tanto em Atenas quanto no santuário extraurbano de Elêusis. No entanto, a intervenção de Adriano que causou maior impacto na Grécia foi a criação do Panhellenion em 131/132 d.C., ano quando também presidiu a cerimônia de dedicação ao recém-construído santuário de Zeus Olímpico em Atenas (IG IV 2 384) (SPAWFORTH, WALKER, 1985, p. 79).

O Panhellenion foi uma liga religiosa fundada com objetivos claros de unificar as cidades gregas sob uma identidade pan-helênica comum. ${ }^{4}$ Muito influenciada pelo contexto da Segunda Sofística, a liga teve, portanto, uma atuação muito marcada no exercício dos ideais da paideia $(\pi \alpha 1 \delta \varepsilon i ́ \alpha)$, se tornando responsável tanto pela organização de jogos e festivais quanto de cultos aos santuários pan-helênicos. Contudo, os critérios para a admissão à liga dependiam da comprovação, por parte das cidades, de descendência dos povos ancestrais gregos (jônios, dórios e eólios), o que se mostrou muito contrário à identidade pan-helênica promovida por meio do exercício da paideia (que se define pela educação na cultura grega) (ROMEO, 2002, p. 21). Porém, essa restrição da participação por meio do critério étnico foi reflexo de uma força presente na Grécia sob domínio romano que procurava manter a hegemonia da narrativa sobre o passado coletivo dos gregos. Além disso, a instituição do Panhellenion subsidiou as relações das elites provinciais das

3 Tal menção se encontra no seguinte trecho da História Augusta: "5. imbutusque inpensius Graecis studiis, ingenio eius sic ad ea declinante, ut a nonnullis Graeculus diceretur” (História Augusta, I, 5).

4 Empregamos o termo "cidades" para imprimir generalidade às organizaçóes que compuseram o Panhellenion, pois além do termo pólis ( $\pi$ ó $\lambda \varepsilon 1 \varsigma$ ), há também o registro de éthne ("̌ $\theta v \eta)$ que, neste caso, se referiam a certas ligas regionais. Uma inscrição de Tessalônica demonstra que o registro da associação das koina tessálica e cretense ao Panhellenion foram representadas sob este termo. (OLIVER, 1978, p. 189-190, no. 1; apud SPAWFORTH, WALKER, 1985, p. 81) 
cidades participantes com Roma, fazendo com que o exercício de cargos na liga se tornasse uma questão de prestígio político. Assim, da mesma forma que o Panhellenion permitiu a integração da Grécia com o Império Romano, também legitimou as intervenções imperiais nas lógicas sociais existentes.

Portanto, este artigo tem o objetivo de analisar a criação do Panhellenion enquanto um projeto consciente de política identitária, cuja implementação foi feita por meio da apropriação de símbolos culturais e da memória coletiva dos gregos do séc. II d.C., particularmente dos atenienses. Nesse sentido, argumenta-se que a escolha por Atenas para sediar o conselho do Panhellenion coloca a cidade em um ponto de convergência da integração das cidades gregas com Roma, o que em grande medida reflete um ideal de pan-helenicidade muito particular. Como veremos, este ideal se fundamentou a partir da perspectiva imperial (interpretatio romana) e tanto sua instituição quanto sua fundamentação implicaram em escolhas que procuravam integrar a Grécia ao Império Romano, sob respaldo do poder e da influência imperiais. Por fim, o argumento se completa a partir da interpretação de como o amplo programa de construçóes públicas realizado em Atenas por Adriano corroborou para materializar o cenário deste processo e conferir legitimidade à existência da liga.

\section{As Reformas da Anfictionia de Delfos: uma primeira EXPERIÊNCIA?}

Primeiramente, é extremamente importante considerarmos o debate historiográfico existente sobre o papel de Adriano nas reformas da Anfictionia de Delfos, pois este é capaz de nos oferecer uma série de elementos para compreender tanto os eventos que precederam a criação quanto a própria natureza do Panhellenion.

A Anfictionia de Delfos foi uma organização muito antiga, cujos registros remontam a períodos anteriores à própria formação da pólis na Grécia Arcaica. Trata-se de uma organização religiosa que congregava um número considerável de comunidades para cuidar da supervisão do santuário de Apolo em Delfos, ou seja, discutir em assembléia assuntos como aqueles relacionados às suas finanças, seus cultos e seus festivais (PAUSÂNIAS, Descrição da Grécia, 10, 8.1-5; LEFÈBVRE, 1995, p. 19-20). Entretanto, Pierre Sánchez e Anthony J. S. Spawforth defendem que há uma interpretação equivocada feita pelos romanos sobre a Anfictionia de Delfos. Eles demonstram que há uma bem conhecida inscrição (FD, III, 2:139) datada do séc. II a.C. em que a 
Anfictionia se dirige a todos os gregos exigindo a aceitação de um novo estilo de moedas atenienses (SÁNCHEZ, 2001, p. 426-428; apud SPAWFORTH, 2012, p. 160). Segundo estes autores, tal ação criou uma tendência em ampliar o alcance do mandato da organização, o que pode ter tido apoio exclusivo de Roma.

Esse argumento pode elucidar como os autores romanos do fim do séc. I a.C. passaram a ver a Anfictionia de Delfos como uma assembleia pan-helênica. Por exemplo, Cícero se refere à Anfictionia como um "conselho comum dos gregos" (CÍCERO, Das Invençóes, II, 69) enquanto que Tito Lívio se refere a um "conselho onde toda Grécia se encontra" (TITO LÍVIO, 33.35, 8). Outras concepções semelhantes são atestadas em escritores do Período Augustano como Dionísio de Halicarnasso (Antiguidades Romanas, 4.25.3-6) e Plínio o Velho (História Natural, 35.35.59). Nesse sentido, Spawforth defende que:

“[...] Vale a pena reafirmar que essa idealização da Anfictionia aparece primeiramente nos autores romanos do Período Republicano, seguidos pelos autores gregos de orientação romana do Período de Augusto. Não há razão para acreditar que os romanos pegaram a ideia de fontes gregas, em vez do contrário. Esta utopia sobre a Anfictionia foi encorajada, senão criada, pelo discurso romano do Período Republicano tardio sobre uma 'Grécia verdadeira.' (SPAWFORTH, 2012, p. 61. Trad. livre dos autores)

Assim, trata-se de uma interpretação feita pelos romanos sobre a Anfictionia de Delfos, o que não significa que, para os gregos, a instituição tenha sido de fato um conselho pan-helênico. De toda forma, uma série de reformas foi realizada na Anfictionia pelos imperadores romanos buscando algo próximo de um ideal pan-helênico.

A reforma de Augusto apresenta mudanças estruturais na instituição, sobretudo na composição das cadeiras representativas. Juan Manuel Copete, em análise de Pausânias (Descrição da Grécia, 10, 8.3-6), demonstra que uma série de outras cidades foram incorporadas na instituição, sendo constituída da seguinte maneira: Nicopolis, cidade simbólica da vitória de Augusto no Ácio e representante do imperador na instituição, era representada por dez conselheiros; os tessálios, por dois; focídios, dois; délfios, dois; dórios, dois (dos quais, um conselheiro pertencia periodicamente à Esparta); jônios, dois (um de Atenas e um da Eubéia); beócios, dois; lócrios, dois. Foi feita também uma simplificação da organização ancestral dos doze povos (COPETE, 1999, p. 94). Assim, a reforma de Augusto procurava por uma integração da Grécia ao mesmo tempo que abria espaço para intervençóes diretas do imperador. 
Contudo, a Anfictionia de Delfos recebe uma contrarreforma durante o Principado de Nero. Uma inscrição encontrada em Delfos (FD, I, 11.1217), datada à época de seu principado, informa que os tessálios passaram a ser representados de dois para doze representantes, o que pode indicar que ocorreu uma redução proporcional no número de representantes de Nicopolis. Copete, assim, afirma que a mudança favorável à Tessália na composição da Anfictionia se deu por conta de uma compensação, resultado de uma mudança do estatuto da região frente ao Império Romano (COPETE, 1999, p. 95), pois a Tessália havia sido um membro de longa tradição histórica. Tal mudança, porém, comprometeu o equilíbrio da instituição, o que ocasionou, a partir de então, uma acentuação dos conflitos dentro das próprias comunidades que a formavam.

Foi esse o cenário da Anfictionia de Delfos que Adriano foi incubido de restaurar no séc. II d.C. Assim, uma famosa inscrição (FD, 3.4, no. 78, coll. 2, linhas 1-6) se tornou fonte para este evento, ainda que não tenhamos até então um consenso sobre sua interpretação. Trata-se, no entanto, de uma recomendação senatorial e o debate acadêmico se concentra em torno de seu aceite ou não pelo imperador e o porquê de tal ação. Datada de 125 d.C., a inscrição contém a sugestão de que Adriano deveria expandir a Anfictionia em algo como "um conselho representativo de todos os gregos", segundo está literalmente escrito, e que os votos dos tessálios deveriam ser repartidos entre atenienses, lacedemônios e membros de outras cidades (COPETE, 1999, p. 96). Por um lado há quem defenda que Adriano intencionou transformar a Anfictionia em um conselho pan-helênico, baseado na inscrição, mas principalmente a partir da atestada similaridade dos aspectos administrativos e organizacionais entre a Anfictionia e o Panhellenion, fundado posteriormente (ROMEO, 2002, p. 25). Nesse sentido, afirmam até que Adriano tentou aplicar as mesmas regras de coletividade e da preeminência ateniense que aplicaria posteriormente no Panhellenion à Anfictionia anos antes e que, em decorrência disso, causou o fracasso da organização délfica. $\mathrm{O}$ modelo seria, portanto, aplicado mais tarde à liga fundada em Atenas (JACQUEMIN, 1991, p. 230; apud ROMEO, 2002, p. 25). Por outro lado, há os já mencionados autores Spawforth e Sánchez que afirmam que Adriano rejeitou a proposta senatorial, pois nunca pretendeu transformar a Anfictionia em "um instrumento de seu programa pan-helênico" (SÁNCHEZ, 2001, 434-435; apud SPAWFORTH, 2012, p. 252). Portanto, defendem que a Anfictionia de Delfos nunca se tornou um conselho pan-helênico de fato, mesmo que as tentativas romanas procurassem atingir este objetivo. Houve, portanto, uma leitura equivocada por parte dos romanos da instituição grega, interpretandothe como um conselho de todas cidades gregas.

No entanto, apesar de haver este debate entre dois lados que interpretam de forma diferente as informações advindas da epigrafia e do relato de 
Pausânias, a controvérsia acadêmica parece nos indicar que a ideia do panhelenismo vinha sendo discutida nas esferas de poder romanas. Nesse sentido, entre os que advogam por ação orquestrada por Adriano, afirma-se que a ampla similaridade entre ambas instituiçóes "permite reconhecer nos planos de Adriano para a Anfictionia um modelo para a composição do núcleo da assembléia Pan-helênica" (ROMEO, 2002, p. 25).

Assim, tal experiência nos permite traçar algumas considerações a respeito da criação do Panhellenion realizada poucos anos depois. Primeiramente, o santuário de Apolo em Delfos tem um caráter pan-helênico, principalmente por conta do funcionamento do oráculo da Pítia, cuja influência sobre o Mundo Grego é historicamente evidente (SCOTT, 2010). Portanto, a experiência romana com a Anfictionia não pode ser descartada de nossa análise, pois as reformas realizadas com a iniciativa imperial indicaram a necessidade romana em legitimar o controle sob as províncias gregas. Era preciso integrar as elites representativas locais com Roma.

O fracasso da Anfictionia em cumprir este objetivo se deu, sobretudo, pelo conflito interno entre os membros, algo ocasionado pela representação desequilibrada. Porém, a Anfictionia de Delfos não esteve presente no projeto pan-helênico de Adriano, como apontam ambas perspectivas historiográficas. Influenciado pela Segunda Sofística e pelo contexto social marcado pela ação de benfeitores, Adriano escolheu o local ideal para fundar seu conselho panhelênico: Atenas. Além disso, esta análise demonstrará que o programa panhelênico realizado poucos anos depois por Adriano, nos moldes como foi feito, apresenta uma concepção identitária, uma pan-helenicidade própria, que se configurou através de uma política fundamentada a partir da ideia de "Grécia" para os romanos e gregos de orientação romana, como veremos a seguir.

\section{Panhellenion: integração de Cidades e a propagação de UMA IDENTIDADE PAN-HELÊNICA}

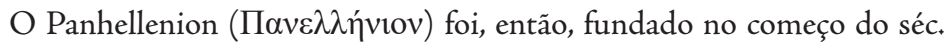
II d.C. (entre 131 e 132) com função de integrar as cidades gregas e abrigar um conselho de todos os gregos. Com sede em Atenas, a criação da liga panhelênica é tanto atribuída à intervenção imperial de Adriano quanto a uma iniciativa independente por parte das comunidades gregas, particularmente das elites alinhadas à Roma (ROMEO, 2002, p. 21-22). O principal objetivo da liga foi congregar as cidades gregas para o exercício de atividades cívicas e religiosas, tais como a organização de cultos e competições em jogos, festivais e outros rituais, relacionando-os à honra do imperador governante (DOUKELLIS, 2007, p. 297).

No entanto, a história do Panhellenion é escrita predominantemente por meio da documentação epigráfica. Numerosas, as inscrições coletadas 
sobre a liga pan-helênica apresentam principalmente informaçóes relativas à administração e a organização do conselho. Assim, no período entre Adriano e os imperadores da dinastia Antonina foram identificadas 33 cidades pertencentes ao Panhellenion, abrangendo regiões como Acaia, Macedônia, Trácia, Ásia, Creta e Cirenaica no Norte da África (Ver Tabela 1 e Figura 1). ${ }^{5}$ Como já mencionamos neste artigo, além de pólis, há também registros da associação de comunidades (éthne) por meio de ligas regionais pois, sozinhas, não conseguiriam sustentar os custos financeiros de uma representação em Atenas. Foram, por exemplo, os casos das koina tessálica (formada por Ípata e Demétrias) e da cretense (formada por Lictos, Gortina e Ierápetra) (SPAWFORTH, WALKER, 1985, p. 80-82).

\begin{tabular}{|l|l|l||}
\hline \multicolumn{2}{|c|}{ Tabela 1: Cidades membros do Panhellenion } \\
\hline Atenas (Ática) & Ípata (Tessália) & Tiatira (Lídia) \\
\hline Esparta (Lacônia) & Demétrias (Tessália) & Sárdis (Lídia) \\
\hline Corinto (Coríntia) & Tessalônica (Macedônia) & Rodes (Rodes) \\
\hline Argos (Argólida) & Perinto (Trácia) & Samos (?) (Samos) \\
\hline Epidauros (Argólida) & Ezani (Frígia) & Apamea (Frígia) \\
\hline Metana (Argólida) & Sínada (Frígia) & Lictos (Creta) \\
\hline Mégara (Megárida) & Eumênia (?) (Frígia) & Gortina (Creta) \\
\hline Cálcis (Eubéia) & Cibira (Lícia/Frígia) & Ierápetra (Creta) \\
\hline Acraifia (Beócia) & Magnésia sobre o Meandro (Cária) & Cirene (Cirenaica) \\
\hline Anficléia (Beócia) & Trales (Cária) & Apolônia (Cirenaica) \\
\hline Narica (Lócrida) & Mileto (Cária) & Ptolemais-Barca (Cirenaica) \\
\hline
\end{tabular}

Fontes: Spawforth Walker, 1985, p. 80, fig. 1; Romeo 2002, p. 23, fig. 1 - Nomenclatura portuguesa a partir de tradução e transliteração com apoio dos termos utilizados no banco de cidades Nausitoo (http://labeca.mae.usp.br/pt-br/city/).

A tabela acima apresenta as cidades cuja associação ao Panhellenion é possível de constatar por meio da epigrafia. Primeiramente, com relação às cidades localizadas no centro da Grécia continental histórica, tais como Esparta, Corinto, Argos, Epidauros, Mégara, Cálcis e as comunidades tessálica, lócrida e beócia, a admissão à liga deve ser automaticamente considerada pois estão atestadas nas inscrições de outras cidades sob o status de "cidades-mães de colônias importantes" (ROMEO, 2002, p. 23-24; JONES, 1996, p. 41). É interessante notar que há uma completa ausência em fontes de qualquer

5 Todas cidades mostradas na tabela são atestadas na fonte epigráfica. No entanto, Eumênia e Samos aparecem com o símbolo (?), pois suas associações à liga são hipotéticas. No caso de Eumênia, a bibliografia considera uma possível a associação à liga por meio de consideraçóes numismáticas (Ver WEISS, 1984, p. 617-637). No caso de Samos é baseado na inscrição IG XII, 6.1, no. 440, porém não há um consenso acadêmico capaz de confirmar a associação de Samos ao Panhellenion. Christopher Jones defende que o termo "panbellenes" da inscrição indica um termo usual da literatura presente no Período Augustano e que não se refere ao Panhellenion de Adriano. A discussão completa se encontra em JONES, C. Augustus and Panhellenes on Samos. Chiron, 2008. p. 107-110. Para a discussão e bibliografia completa sobre a associação das cidades a Panhellenion ver: SPAWFORTH, WALKER, 1985; ROMEO, 2002; DOUKELLIS, 2007. 
tipo com relação à admissão de cidades da Magna Grécia, tais como Siracusa, Metaponto ou Posidônia, por exemplo, cuja importância histórica nos é comprovada graças à pesquisa arqueológica (FLORENZANO, HIRATA, 2009; FLORENZANO, KORMIKIARI, HIRATA, 2012). Além disso, há também uma completa ausência de qualquer tipo de ligação ao Panhellenion de cidades da Ásia Menor de importância cultural intensa durante o Período Romano, como são os casos de Esmirna, Éfeso e Pérgamo (RICCARDI, 2007, p. 383). Esses dados são importantes e voltaremos a eles mais tarde.

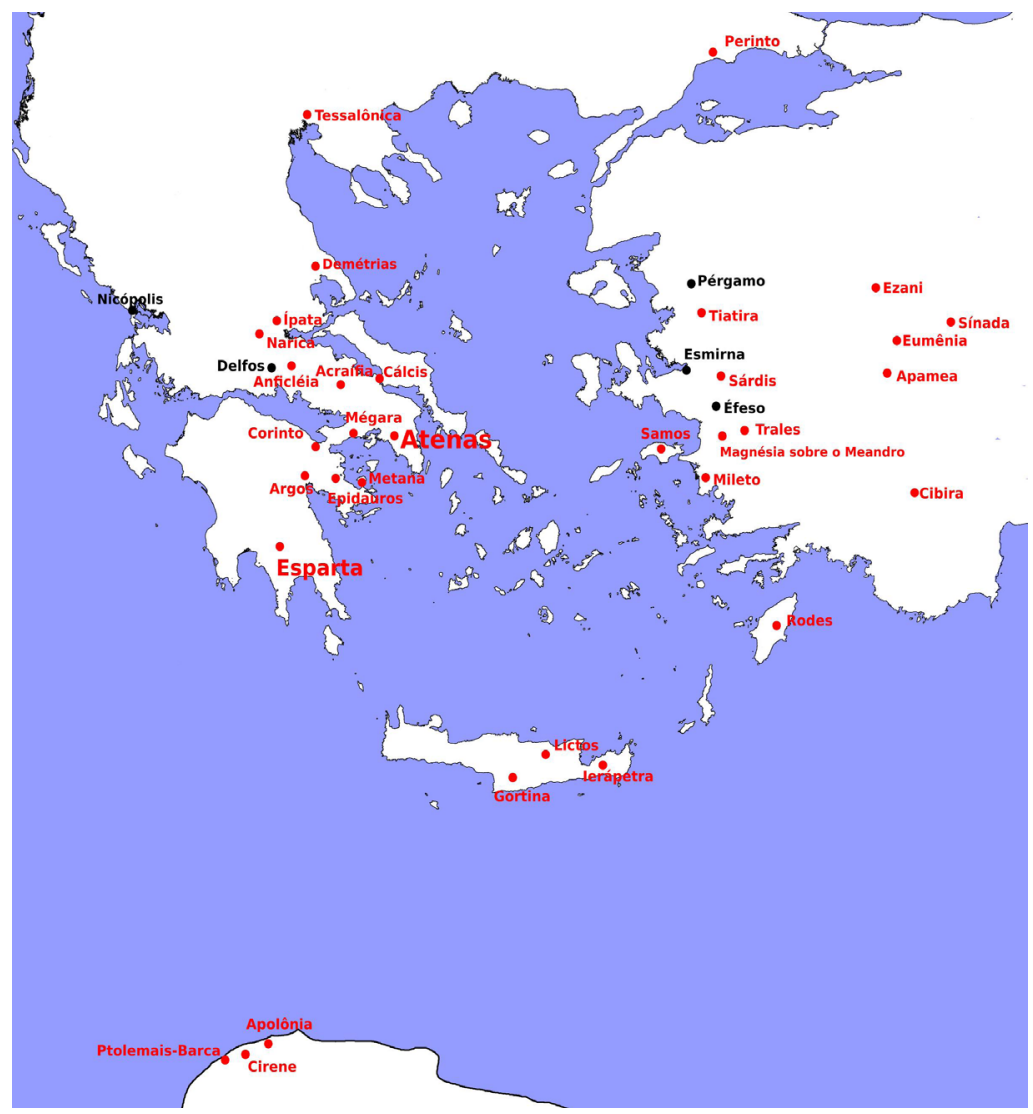

Fig. 1: Mapa com as cidades membros do Panhellenion marcadas em vermelho e demais cidades mencionadas no texto em preto (Modificado a partir dos mapas livres oferecidos pela Escola Americana de Estudos Clássicos de Atenas. ${ }^{6}$ Confecção: Felipe Perissato)

6 Os mapas livres da Escola Americana de Estudos Clássicos de Atenas são oferecidos sob a licença livre Creative Commons e estão à disposição para o uso de pesquisadores em seu site oficial, no seguinte link: <http://www.ascsa.edu.gr/index.php/excavationcorinth/maps-and-gisdata-for-corinth-and-greece $>$. Acesso em: 06 de novembro de 2017. As informações utilizadas neste mapa foram coletadas a partir dos estudos de Romeo, 2002 e Spawforth, Walker, 1985. 
As fontes epigráficas que atestam a associação das demais cidades ao Panhellenion (conforme apresentamos em nossa Tabela 1) demonstram um aspecto identitário bastante interessante sobre o critério levado em consideração pelo conselho. Associar-se à liga, portanto, dependia de uma série de ações que os representantes das cidades requerentes deveriam apresentar, quando precisavam comprovar serem gregos "de origem" (DOUKELLIS, 2007, p. 297-298). Trata-se de um processo que Panagiotis Doukellis chama de "identização":

“O processo de 'identização', que é a expressão da identidade desejada por aqueles que a procuravam, está relacionada com o uso do passado que passa por um processo de identificação realizado por uma autoridade mais poderosa. No caso do Panhellenion, a identificação era feita pelo próprio imperador, que se encarregava de aceitar os argumentos que promoviam Helenicidade, ou rejeitá-los." (DOUKELLIS, 2007, p. 299)

Um caso bastante elucidativo destes processos de "identização" por parte da cidade e de "identificação" por parte da autoridade sobre o Panhellenion é o caso da filiação de Ptolemais-Barca (Cirenaica). Em uma inscrição (SEG 46.2206) não só fica evidente esse tipo de relação, como demonstra que dependendo de como a genealogia étnica da cidade é composta e apresentada, o conselho pode instituir associações de diferentes graus à liga:

"[O povo de Ptolemais-Barca] deve ser admitido [ao Panhellenion]. Contudo, eles fazem o pedido injustificado [ao desejar os mesmos (privilégios) que o povo de Cirene, cuja] ancestralidade é aquéia e perfeitamente dórica. Embora eles próprios sejam verdadeiros [gregos], possuem o nome adicional de [Ptoloma]icos pelo fato de [os Macedônios (?)] quando eram mestres [(da terra?)] renomearam [(reassentaram, restauraram?)] a cidade. Já que cirenenses estão enviando dois delegados, [é a minha decisão que o barcenses enviem somente um]" (apud DOUKELLIS, 2007, p. 300) ${ }^{7}$

A inscrição trata de uma intervenção direta do imperador a um arconte do Panhellenion a respeito dos critérios utilizados para verificar uma disputa entre duas cidades da Cirenaica que buscavam associação à liga. Embora o esforço de Jones (1996, p. 45) em reconstituir a inscrição seja muito significativo, seu conteúdo é bastante fragmentado. Porém, graças ao seu trabalho é possível

7 Tradução para o inglês de Jones, 1996, p. 45. Apud Doukellis, 2007, p. 300. Tradução portuguesa nossa. 
constatar que o imperador procura uma solução por meio do emprego do critério identitário que demonstramos neste artigo. Assim, as duas cidades são admitidas no Panhellenion, porém Cirene, por conta de sua "ancestralidade original grega”, tem direito a mais representantes que Ptolemais-Barca, cuja identidade é "diluída" entre elementos tardo-helenísticos (a descendência ptolomaica) (ROMEO, 2002, p. 26-27; DOUKELLIS, 2007, p. 299-300; SPAWFORTH, 2012, p. 252-253).

Outro caso em que fica evidente o processo de identização é uma inscrição datada do Período Antonino-Severiano (OGI 2.497), em que atesta o argumento da cidade de Cibira (Lícia/Frígia). Admitida ao Panhellenion, a cidade se declara ao mesmo tempo uma colônia de Esparta, com ancestralidade também relacionada à Atenas (syngenes), e parceira de Roma (SPAWFORTH, WALKER, 1985, p. 82; ROMEO, 2002, p. 26).

Há também cidades que recorrem a mitos de fundação, buscam relações com as cidades-mães e até demonstram relações de ancestralidade com outras cidades importantes do ponto de vista identitário, o que deve ser entendido dentro da concepção pan-helênica do Período Romano. Um decreto ateniense feito pelo Panhellenion a respeito da situação de Magnésia sobre o Meandro (Cária) (IG II ${ }^{2}$ 1091) demonstra, por exemplo, que a cidade, uma colônia dos magnésios da Tessália, faz referências explícitas à aliança histórica da cidade com os jônios, dórios e com os "irmãos de sangue" eólios da Ásia Menor. Além disso, há a defesa de ancestralidade com a Tessália por meio do argumento que seu fundador, Leucipo, foi pertencente à linhagem de Éolo, rei mítico da Tessália (ROMEO, 2002, p. 27; SPAWFORTH, WALKER, 1985, p. 82). Algo parecido acontece com a cidade frígia de Sínada que compóe sua genealogia mítica de modo que possa justificar ligação entre sua fundação e as cidades de Atenas e Esparta. Inclusive, na época do Panhellenion, entre os sécs. II e III d.C., uma série de moedas são cunhadas em Sínada recordando suas origens dóricas e jônicas. (ROBERT, 1950, p. 90; apud ROMEO, 2002, p. 28).

Assim, Ilaria Romeo (2002) defende corretamente que o Panhellenion utiliza de uma política identitária que se baseia predominantemente por uma concepção étnica, em que a helenicidade é definida por nascimento e pelo o que se entendia por etnia. É por isso a necessidade em controlar o acesso à liga por meio da comprovação de ascendência aos genos helênicos (sobretudo dos elementos jônicos, dóricos e eólicos). No entanto, tal concepção pan-helênica é conflitante com o pan-helenismo típico do contexto baseado na concepção da paideia, ou seja, em que a helenicidade é definida por meio da educação na cultura grega. (ROMEO, 2002, p. 21-40). 
A ideologia pan-helênica promovida pelo Panhellenion partia, portanto, de um pressuposto romano. Não somente por ter sido uma instituição de iniciativa imperial e das elites provinciais alinhadas com Roma, mas possuindo um modelo de política identitária que partia de uma leitura romana sobre a Grécia. Essa interpretatio romana, como aponta Anthony J. S. Spawforth, destacava principalmente uma Grécia lida a partir dos centros históricos da Grécia Continental, sobretudo da Ática (tal concepção de “Graecia uera” aparece, por exemplo, em Cícero (Retórica a Herênio, 4, 25.1), em Plínio O Velho (História Natural, 4, 1.1) e em Sêneca (Suasórias, 2.5). ${ }^{8}$ Afinal, como afirma esse autor, a Grécia "velha" ou "verdadeira", localizada na Europa e contendo as cidades gregas mais "nobres" e "notáveis", tais como Atenas e Esparta, por exemplo, tinham um posto de primazia que acabou sendo institucionalizado e alavancado com a criação do Panhellenion (SPAWFORTH, 2012, p. 253; RICCARDI, 2007, p. 383-384). Esse aspecto pode indicar para o motivo da ausência de menções a cidades que também foram centros de primazia cultural, mas que não estavam no centro da ideologia pan-helênica da instituição, como foram os casos de Esmirna, Éfeso e Pérgamo. ${ }^{9}$ Esse aspecto ideológico também indica pistas para justificar a ausência de cidades da Magna Grécia na composição do conselho.

Dessa forma, o Panhellenion promovia um modelo de integração das cidades gregas através de uma política identitária bastante particular no contexto de sua criação. Ao mesmo tempo que garantia uma mobilidade das elites provinciais, estreitando as relações com Roma, o imperador detinha influência direta legitimada nas províncias gregas por meio das intervenções na liga, como ficou claro na análise de algumas inscrições.

\section{O coração da Liga: Atenas e o programa construtivo de Adriano}

O modelo de integração que o Panhellenion propunha tinha, portanto, um ponto de convergência. A escolha por Atenas para sediar o conselho da liga está relacionada à ideologia pan-helênica construída no período, quando o caráter histórico e cultural da cidade é colocado em primazia (GRECO, 2011, p. 392). Assim, o contexto da criação da liga pan-helênica e do impacto desta

\footnotetext{
8 Para a discussão completa sobre o discurso da "Grécia verdadeira" pelos autores romanos ver os capítulos "Introduction: Greece and the Augustan Age" e"Athenian eloquence and Spartan arms" de SPAWFORTH, 2012.

9 Apesar disso, essas cidades mantiveram relações importantes com Roma, o que é demonstrado sobretudo por meio da cultura material. Ver BOATWRIGHT, 2000.
} 
na vida provincial oferecem embasamento para compreendermos o contexto arqueológico das construçóes realizadas em Atenas durante o principado de Adriano. Afinal, como argumenta Anthony J. S. Spawforth:

"A escala e a qualidade das novas construções de Adriano em Atenas superaram qualquer outra benfeitoria imperial feita em uma cidade provincial. $\mathrm{O}$ engrandecimento do ambiente construído para demonstrar uma atualização imperial do estatuto da cidade foi uma prática bem romana do ponto de vista ideológico. O propósito deste aprimoramento de Adriano, como já argumentado, teve o objetivo de sinalizar para a excepcionalidade cultural de Atenas na perspectiva do estado imperial e, em específico, tornar a cidade arquitetonicamente adequada para sediar uma nova instituição: o Panhellenion Ático." (SPAWFORTH, 2012, p. 248-249)

Vale lembrar que esse tipo de política que procura estabelecer influência por meio da prática de oferecimento de doações e benfeitorias, como é o caso das construções, é aspecto chave do contexto da Grécia durante o Período Romano. Na verdade, o evergetismo foi uma herança mais antiga, estabelecida na Grécia a partir do aumento da influência das monarquias helenísticas. ${ }^{10}$ Contudo, as construções e reformas em Atenas promovidas por Adriano possuem um aspecto lógico e, como demonstra Spawforth no trecho aqui citado, é possível considerá-lo um projeto relacionado com a criação do Panhellenion, pois ambos dialogam com o contexto urbano de Atenas do séc. II d.C. É dessa forma, portanto, que as construções adriânicas em Atenas são compreendidas por meio da noção de "programa construtivo" (SPAWFORTH, 2012, p. 247; ÉTIENNE, 2004, p. 200-205) e, assim, oferecem fundamento para os respectivos contextos arqueológicos.

A escolha de Adriano por Atenas como sede do Panhellenion não é somente resultado de sua afeição pessoal à cidade, como lembram Spawforth e Walker (1985, p. 90), mas é reflexo de uma perspectiva muito comum entre

10 Os romanos, portanto, estabeleceram sua influência já na República, quando se inseriram na lógica das relações sociais existente. Há uma extensa literatura a respeito do evergetismo. Sobre o evergetismo especificamente romano na Grécia destacamos duas obras bem recentes: A primeira de EILERS, C. Roman Patrons of Greek Cities. Oxford: Oxford University Press, 2002; e a de ZUIDERHOEK, A. Oligarchs and Benefactors. Elite demography and euergetism in the Greek East of the Roman Empire. In: VAN NIJF, O; ALSTON, R. Political Culture in the Greek City after the Classical Age. Peeters, 2011; E sobre evergetismo helenístico e augustano em Atenas, destaca-se a tese de MORALES, F. A. Atenas e o Mediterrâneo Romano: espaço, evergetismo e integração. Tese de Doutorado. Faculdade de Filosofia, Letras e Ciências Humanas da Universidade de São Paulo. 2015. 
gregos e romanos "helenizados" de que Atenas era o berço da civilização grega. Nesse sentido, muito se deve ao fato de que os Mistérios Eleusinos, culto às deusas agrícolas Deméter e Core localizado na khóra ateniense, tinha uma centralidade no mundo pan-helênico (e mediterrânico após os romanos) (ANTONETTI, 1995, p. 149-156). ${ }^{11}$ Isso se deve ao fato de que o mito propagava historicamente Atenas na figura de Triptólemo, o herói responsável por espalhar os ensinamentos da agricultura ao mundo. Assim, em famosa passagem de Cícero fica evidente essa perspectiva:

\begin{abstract}
"Entre muitas instituições incríveis e de fato divinas nos quais Atenas produziu e contribuiu à vida humana, nenhuma, em minha opinião, é melhor do que aqueles mistérios. Graças a eles, nós saímos de nosso modo de vida bárbaro e selvagem e nos educamos e refinamos a um estado de civilização; e como os ritos são chamados de "iniciações", então verdadeiramente aprendemos com eles as primícias da vida, e ganhamos força não somente para vivermos mais felizes, mas também morrermos com uma esperança melhor." (CÍCERO, De Legibus II, XIV, 36)
\end{abstract}

Dessa maneira, uma série de intervenções foram feitas em Atenas e no santuário em Elêusis tanto como iniciativa imperial quanto fruto da ação das próprias elites romanas e provinciais. Cássio Dio é uma das fontes escritas que menciona as intervenções de Adriano em Atenas. Em uma passagem fica relatado que o próprio imperador fez uma generosa doação de grãos à cidade (provavelmente ao santuário eleusino), além de muitas construções, entre obras de engenharia, monumentos e restauro de santuários importantes (CÁSSIO DIO, LXIX, 16, 1-3; SPAWFORTH, WALKER, 1985, p. 90). Ele também empreende uma série de reformas agonísticas, quando revitaliza as Panatenaias e funda três novos festivais: as Olimpieias, as Adrianeias e as Panhellenias (SPAWFORTH, 2012, p. 248).

Os estudos sobre a topografia de Atenas surgiram a partir do séc. $\mathrm{XIX}$, mas se consolidaram sobretudo no XX, fruto do desenvolvimento do trabalho arqueológico. Assim, várias edificações foram descobertas a partir das intervenções arqueológicas na cidade desde escavações sistemáticas até escavações pontuais de salvamento. Diversos edifícios foram datados para a época de Adriano como, por exemplo, aqueles que se figuram nas fontes escritas de Pausânias e Cássio Dio, como a Biblioteca de Adriano e o restauro da Ágora Romana; obras de engenharia para melhor infraestrutura da cidade, tais como a construção de um aqueduto para oferecimento de água potável no Ninfeu monumental situado no centro da ágora; cisternas,

11 Seguimos a sistematização dos termos espaciais gregos realizada pela equipe do Labeca (MAEUSP) em: <http://labeca.mae.usp.br/pt-br/glossary/ > . 
obras de canalização, pontes sobre o rio Eridanos e sobre o rio Kephissos (no caminho para Elêusis); um quarteirão inteiro conhecido como "cidade de Adriano", onde consta a edificação de um Arco Triunfal (Fig. 5); é feito o acabamento do Templo de Zeus Olímpico (Fig. 2 e 3), edificou-se também Templos de Zeus Panhellenios e Hera Panhellenia que são entendidos como fundamentais para o contexto do Panhellenion (TRAVLOS, 1970, p. 429; SPAWFORTH, WALKER, 1985, p. 92-100). Há também edifícios cuja datação é creditada ao Período Adriânico, porém as fontes são fragmentárias e não permitem uma identificação precisa, o que tem propiciado um intenso debate entre os especialistas. São os casos do Pantheon, localizado à oeste da Biblioteca de Adriano e de um possível ginásio localizado a sul do Rio Ilisso (BOATWRIGHT, 2000, p. 144-157; SPAWFORTH, WALKER, p. 94). ${ }^{12}$

Um caso muito interessante são as obras no Templo de Zeus Olímpico. Sendo a figura de Zeus Olímpico central na ideologia pan-helênica promovida por Adriano e também para o exercício do culto imperial, o projeto deste santuário monumental foi idealizado séculos antes por Péricles como um templo períptero dórico (TRAVLOS, 1980, 402-403). Como sua construção nunca se finalizou, Adriano encontrou uma oportunidade para fazer a benfeitoria à Atenas e também monumentalizar sua influência. $\mathrm{O}$ Templo de Zeus Olímpico foi então construído seguindo a ordem coríntia, sobretudo a partir da variação decorrente da apropriação romana desta ordem (ABRAMSON, 1974, p. 1-3; WYCHERLEY, 1974, p. 155-174). Isso fica evidente nos adornos talhados no capitel de algumas colunas que ainda se encontram in situ (Ver Figuras 2 e 3).

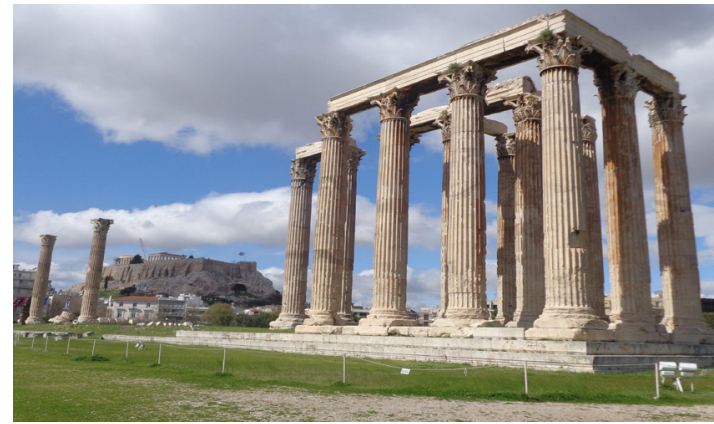

Fig. 2: Fotografia do Templo de Zeus Olímpico (Acervo pessoal, 2014)

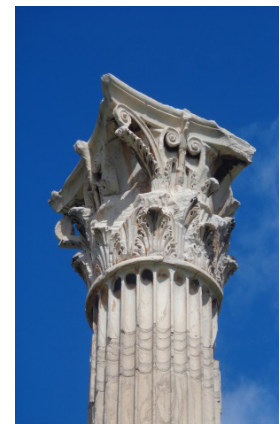

Fig. 3: Capitel coríntio do Olympieion (Acervo pessoal, 2014) 
Além disso, há uma intensa atividade construtiva no santuário de Elêusis, situado na khóra de Atenas. Sendo os Mistérios de Elêusis um culto que tem um papel central na ideologia do Panhellenion, tanto Adriano (e os imperadores posteriores) quanto a própria elite romana e grega provincial (inclusive, o próprio Panhellenion) foram responsáveis por monumentalizar o santuário. Destacam-se, nesse sentido, principalmente obras de adorno, como dois arcos triunfais (construídos como cópias do arco romano de Atenas, onde em seus pedimentos constam inscrições dedicatórias mostrando que foram doações do Panhellenion às deusas e ao imperador - Ver Figuras 4, 5 e 6) e um propileu monumental cuja forma presta homenagens ao Propileu de Mnesícles do séc. V a.C; obras e restauros de templos, como a construção do Templo de Ártemis e Poseidon e outros dois templos que seguem uma tipologia romana; obras de engenharia, como um aqueduto, uma fonte, duas cisternas, obras de canalização e a já mencionada ponte sobre o Kephissos localizada no Caminho Sagrado (MYLONAS, 1961; CLINTON, 1989; LIPPOLIS, 2008; PERISSATO, 2017).

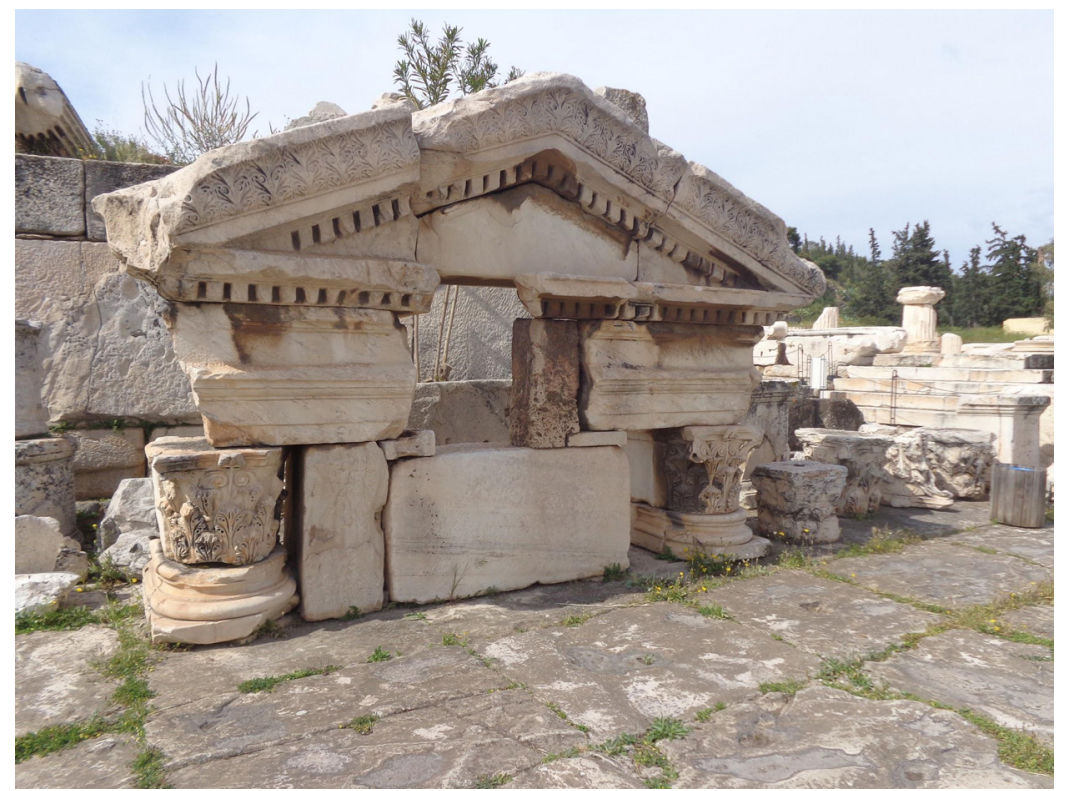

Fig. 4: Fragmentos da membratura arquitetônica do Arco Triunfal leste em Elêusis in situ (Acervo pessoal, 2016) 


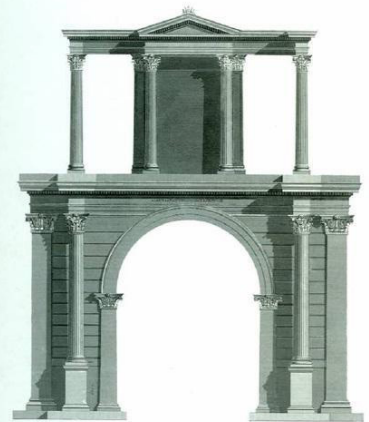

Fig. 5: Reconstituição de Arco Triunfal de Elêusis (WILLERS, 1990).

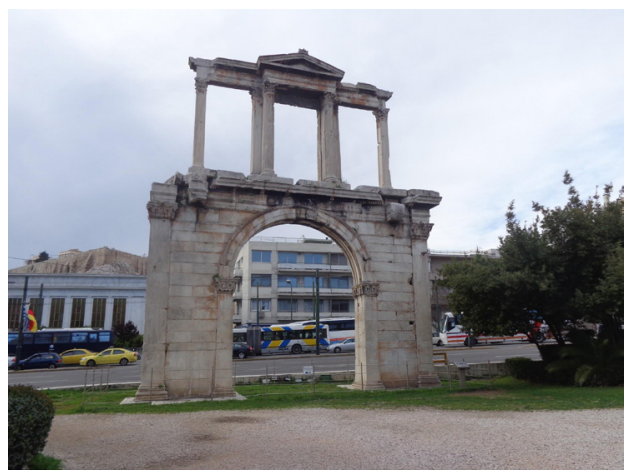

Fig. 6: Arco de Adriano em Atenas

(Acervo pessoal, 2014).

Assim sendo, os casos aqui utilizados como exemplo do programa construtivo de Adriano demonstram o caráter central dado à Atenas tanto pela instituição do Panhellenion quanto pela própria ideologia pan-helênica que se pretendia solidificar. A arquitetura, seus símbolos e a edificação de diversos monumentos dialogavam com o próprio contexto evergético do período, o que em grande medida presta legitimidade à existência da liga pan-helênica e da influência imperial sobre um "Mundo grego" muito particular e específico construído pelo viés romano e grego provincial do séc. II d.C.

Portanto, é possível afirmar que esse fluxo de ideologia pan-helênica é responsável por colocar Atenas no centro da integração da Grécia no Mediterrâneo Romano.

\section{Conclusão}

Assim, este artigo teve o principal objetivo de analisar a criação do Panhellenion como um projeto de política identitária aplicada na Grécia sob a iniciativa tanto imperial quanto das elites provinciais aliadas à Roma. A discussão em torno da experiência romana com a Anfictionia de Delfos nos permitiu compreender alguns aspectos das intervenções feitas pelos imperadores na Grécia, além de constatar a necessidade, por parte de Roma, de se criar um organismo que centralizasse as relações entre as cidades gregas, possibilitando tanto um modelo de integração da região com o Império quanto garantindo uma atuação mediadora do poder imperial. Assim, nossa reflexão sobre o contexto de criação do Panhellenion caminhou tanto pela análise das inscrições relacionadas aos processos de associação das cidades pretendentes à 
instituição quanto pelos programas construtivos empregados em Atenas, sede do conselho pan-helênico.

Em ambas análises foi possível constatar elementos que são compostos por meio de apropriações de símbolos culturais e da memória coletiva dos gregos, seja pelo critérios identitários utilizados pelo Panhellenion para selecionar as cidades participantes do conselho da instituição, seja pelas construções edificadas ou reformadas em Atenas. Como vimos, esse modelo de integração baseado numa "Grécia verdadeira", concepção que foi fruto da apropriação seletiva do passado clássico grego realizado tanto pela leitura de gregos provinciais quanto de romanos, solidificou a primazia de Atenas como centro do pan-helenismo e da integração da Grécia com o Império Romano. Esse processo permitiu também conferir legitimidade à criação do Panhellenion.

\begin{abstract}
The creation of the Panhellenion in II century A.D. was a project of imperial and provincial elites initiatives that intended to integrate Greece in the Roman Empire. The league was a council located in Athens that cultivated a very specific panhellenic identity conception, whose function was related to the organization of panhellenic cults, games and festivals. This aspect was evident in the inscriptions that registrate the association of greek cities to the league as well as in the constructive program established in Athens by Hadrian. Therefore, this paper has the objective of analyzing the creation of Panhellenion as a conscious project of identity politics, because it intended to disseminate a very specific idea of panhellenism, whose constitution was based in a Roman reading of Greece. Besides that, the choice for Athens as a center to the panhellenic council provided its consolidation as a convergent center of integration of the greek cities with Rome.
\end{abstract}

Keywords: Panhellenion, Hadrian, Ethnic identity, Roman Greece, Mediterranean Integration, Evergetism.

\title{
REFERÊNCIAS BibLIOGRÁfiCAS
}

\section{Fontes Antigas:}

CICERO. On the Republic. On the Laws. Loeb Classical Library 213, Translated by Clinton W. Keyes, Harvard University Press, Harvard, 1928.

CICERO. On Invention. The Best Kind of Orator. Topics. Loeb Classical Library 386, Translated by H. M. Hubbell. Harvard, 1949.

DIONYSSUS OF HALICARNASSUS. Roman Antiquities, Loeb Classical Library 319, Translated by Earnest Cary. Harvard, 1937.

LIVY. History of Rome. Vol. 1. Loeb Classical Library 114. Translated by B. O. Foster. Harvard, 1919. 
HISTÓRIA AUGUSTA. Vol 1. Vidas de Adriano, Élio, Antonino Pio, Marco Aurélio, Lúcio Vero, Avídio Cássio e Cómodo. Trad.: TEIXEIRA, C. A; BRANDÃO, J. L; RODRIGUES, N. S. Centro de Estudos Clássicos e Humanísticos, Coimbra, 2011.

PAUSANIAS, Description of Greece. Vol. IV. Book 8-10. Loeb Classical Library 297. Translated by W. H. S. Jones. Harvard, 1935.

PLINY THE ELDER. Natural History. Vol. 1. Loeb Classical Library 330. Translated by H. Rackham. Harvard, 1938.

SENECA THE ELDER. Declamations, Volume II: Controversiae, Books 7-10. Suasoriae. Fragments. Loeb Classical Library 464. Translated by M. Winterbottom, 1974.

Catálogos epigráficos:

CLINTON, Kevin. Eleusis. The Inscriptions on Stone: Documents of the Sanctuary of the two Goddesses and public documents of the deme, Volumes I and II. Athens: The Archaeological Society of Athens, 2005.

FOUILLES DE DELPHES (FD). École française d'Athènes, Paris: E. de Boccard. 1848-1925. Disponível online em: <https://archive.org/details/ fouillesdedelphe03ecoluoft $>$ Acesso: 17 de outubro de 2017; E também em: PHI Greek Inscriptions <http://epigraphy.packhum.org/regions/1311> Acesso: 18 de outubro de 2017.

Sites:

Athenian Agora Excavations. The American School of Classical Studies at Athens. <http://agathe.gr > Acesso: 20 de outubro de 2017.

Banco de dados sobre as cidades antigas Nausitoo - Laboratório de Estudos sobre a Cidade Antiga - LABECA (MAE-USP). <http://labeca.mae.usp.br/pt-br/city/> Acesso: 17 de outubro de 2017.

Bibliografia geral:

ABRAMSON, Hebert. The Olympieion in Athens and Its Connections with Rome. California Studies in Classical Antiquity, California, Vol. 7, 1974. p. 1-25.

ANTONETTI, Claudia. La Centralità di Eleusi nell'Ideologia Panellenica Adrianea, Ostraka: Rivista di Antichità, Napoli, Anno IV, n.1, 1995. p. 149-156.

ANTONETTI, Claudia. I Panhellenes dalla Grecia Arcaica al Tardo Impero: l'unità irrealizzabile. Ostraka: Rivista di antichità, Napoli, Anno V, n. 1., 1996. p. 9-14.

BENJAMIN, Anna S. The Altars of Hadrian in Athens and Hadrian's Panhellenic Program. Hesperia: The Journal of the American School of Classical Studies at Athens, Athens, Vol. 32, 1963. p. 57-86.

BENJAMIN, Anna S. Two Dedications in Athens to Archons of the Panhellenion. Hesperia: The Journal of the American School of Classical Studies at Athens, Athens, Vol. 37, No. 3. 1968. p. 338-344. 
BOATWRIGHT, Mary T. Hadrian and the Cities of the Roman Empire. New Jersey: Princeton University Press, 2000.

BOATWRIGHT, M. T. Further Thoughts on Hadrianic Athens. Hesperiaः The Journal of the American School of Classical Studies at Athens, Athens, Vol. 52, No. 2, 1983. p. 173-176.

CLINTON, Kevin. Hadrian's contribution to the renaissance of Eleusis. In: WALKER, Susan; CAMERON, Averil. (org.). The Greek Renaissance in the Roman Empire. Papers of the 10th British Museum Classical Colloquium, London, BIC Supplement Vol. 55, 1989. p. 56-68.

COPETE, Juan Manuel C. El fracasso del primer proyeto panhelénico de Adriano.

Dialogues d'histoire ancienne, Franche-Comté, v. 25, n. 25-2, 1999. p. 91-112.

DOUKELLIS, Panagiotis. N. Hadrian's Panhellenion: A network of cities?.

Mediterranean Historical Review, London, Vol. 22, No. 2. 2007. p. 295-308

ÉTIENNE, Roland. Athènes. Espaces urbains et histoire. Des origines à la fin du IIIe siècle ap. J-C. Paris: Hachette Superieure, 2004.

FLORENZANO, M. B. B; HIRATA, E. F. V. (orgs.). Estudos sobre a Cidade Antiga, São Paulo: EDUSP. 2009.

FLORENZANO, Maria Beatriz B.; KORMIKIARI, Maria Cristina N.; HIRATA, Elaine F. V. (orgs.). Estudos sobre o Espaço na Antiguidade. São Paulo: Edusp. 2012.

GRAINDOR, Pierre. Athènes sous Hadrien, Cairo: Impremerie Nationale, 1934. GRECO, Emanuele. Topografia di Atene: Sviluppo urbano e monumenti dalle origini all III secolo d.C., Tomo 2: Colline sud-occidentali - Valle dell'Ilisso. AtenePaestum: Pandemos, 2011.

JACQUEMIN, Anne. Delphes au II a siècle ap. J.C. In: SAID, S. (ed.). Hellenismos: Quelques jalons pour une histoire de l'identité grecque. Actes du Colloque 1989, Leiden, 1991, p. 217-232.

JONES, Christopher P. The Panhellenion. Chiron: Mitteilungen der Komission für Alte Geschichte und Epigraphik des Deutschen Archäologischen, vol. 26. 1996. p. 29-56.

LARSEN, Jakob A. O. Cyrene and The Panhellenion. Classical Philology, Chicago, Vol. 47, No. 1, 1952. p. 7-16.

LEFÈBVRE, François. L'Amphictionie de Delphes: mythe et réalité. Cahiers du Centre Gustave Glotz, Paris, Vol. 6, no. 1, 1995. p. 19-31.

LIPPOLIS, Enzo. Eleusi, santuario dell'Impero, Bolletino di Archeologia Online, Volume Speciale, International Congress of Classical Archaeology Meetings between cultures in the Ancient Mediterranean, Roma, 2008. p. 34-46

MALKIN, Irad; CONSTANTAKOPOULOU, Christy; PANAGOPOULOU, Katerina. (ed.). Greek and Roman Networks in the Mediterranean. London: Routledge, 2009.

MYLONAS, George. Eleusis and the Eleusinian Mysteries. Priceton: Princeton University Press. 1961.

OLIVER, James H. Documents Concerning the Emperor Hadrian, Hesperia: The Journal of the American School of Classical Studies at Athens, Athens, Vol. 10, No. 4, 1941. p. 361-370.

OLIVER, James H. New Evidence on the Attic Panhellenion. Hesperia: The Journal of the American School of Classical Studies at Athens, vol. 20, no. 1,1951. p. 31-33 
OLIVER, James H. Marcus Aurelius: Aspects of Civic and Cultural Policy in the East. Hesperia Supplements, Vol. 13. Athens, 1970. p. 1-168.

OLIVER, James H. Panachaeans and Panhellenes. Hesperia: The Journal of the American School of Classical Studies at Athens, Vol. 47, n. 2, 1978, p. 185-191.

PERISSATO, Felipe. Eleusis and the Eleusinian myth in the Roman Period. In: PONTRANDOLFO, Angela; SCAFURO, Michele. (org.). Dialoghi sull'Archeologia della Magna Grecia e del Mediterraneo Antico, Vol. 3, Paestum, 2017. p. 683-690.

RICCARDI, Lee A. The Bust-Crown, the Panhellenion, and Eleusis: A New Portrait from the Athenian Agora. Hesperia: The Journal of the American School of Classical Studies at Athens, Athens, Vol. 76, No. 2, 2007. p. 365-390.

ROBERT, Louis. Hellenica: Recueil d'épigraphie, de numismatique et d'antiquités grecques. Vol. 8. 1950, p. 1-103.

ROMEO, Ilaria. The Panhellenion and Ethnic Identity in Hadrianic Greece. Classical Philology, Chicago, Vol. 97, No. 1, 2002. p. 21-40.

SÁNCHEZ, Pierre. LAmphictionie des Pyles et de Delphes: recherches sur son rôle historique des origines au II . siècle de notre ère, Historia Einzelschriften, Stuttgart, vol. 148. 2001.

SCOTT, Michael. Delphi and Olympia: the politics of panhellenism in the Archaic and Classical Periods. Oxford: Oxford University Press. 2010.

SPAWFORTH, Anthony J. S. Greece and the Augustan Cultural Revolution. Cambridge: Cambridge University Press, 2012.

SPAWFORTH, Anthony J. S.; WALKER, Susan. The World of the Panhellenion. I. Athens and Eleusis. The Journal of Roman Studies, London, Vol. 75, 1985. p. 78 104.

SPAWFORTH, Anthony J. S.; WALKER, Susan. The World of Panhellenion. II. Three Dorian Cities. The Journal of Roman Studies, London, Vol. 76. 1986. p. 88105.

WYCHERLEY, Richard E. The Stones of Athens. Princeton: Princeton University Press, 1974.

TRAVLOS, John. The Pictorial Dictionary of Ancient Athens. New York: Hacker Art Books, 1980.

VLIZOS, Stavros (org.). Athens during the Roman Period: Recent Discoveries, New Evidence. Athens: Mouseio Benaki, 2008.

WEISS, Peter. Lebendiger Mythos. Gründerheroen und städische Gründungstraditionen im grieschisch-römische Osten. Würzburger Jahrbücher für die Altertumswissenschaft neue Folge, Heidelberg, vol. 10. 1984. p. 179-208.

WILLERS, Dietrich. Hadrians panhellenisches Programm: Archäologische Beiträge zur Neugestaltang Athens durch Hadrian. Antike Kunst Supplement 16. Basel. 1990.

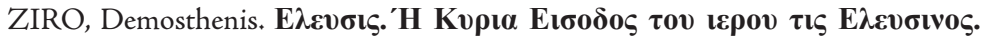

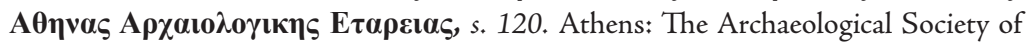
Athens, 1991. 